\title{
РЕАЛИЗАЦИЯ РЕГИОНАЛЬНОЙ ПОЛИТИКИ ЭНЕРГОСБЕРЕЖЕНИЯ В ПРОМЫШЛЕННОМ СЕКТОРЕ НА ПРИМЕРЕ ВЛАДИМИРСКОЙ ОБЛАСТИ
}

\section{Кудряков Р.И.}

Данное исследование посвящено проведению анализа и выявлению эффективности от проведения региональной политики энергосбережения в промышленном секторе региона Владимирской области. В статье рассмотрен теоретико-понятийный аппарат, проведен детализированный анализ использования энергоэффективных технологий в промышленном секторе Владимирской области, с процедурой оченки эффективности текущего использования и составлением прогноза и рекомендаций по популяризации применения таких технологий в промьшленном производстве.

Цель исследования: выделением проблематики и потенциала при текущей реализации региональной политики энергосбережения в промышленном секторе Владимирской области, с последующей разработкой мероприятий по стабилизации выпеуказанных негативных аспектов и прогноза повышения эффективности.

Методы и методология: комплекс методов статистического, системного, сравнительного анализа. Обоснована система по диагностике совокупного энергетического потенциала, оказывающих на него непосредственное влияние с учетом разработанных стабилизационных мероприятий.

Результаты исследования: выделены основные проблемы при помощи комплексного анализа по использованию энергоэффективных технологий в промышленном секторе региона, а также разработан перечень мероприятий по стабилизации текущих проблемных моментов, также, составлен прогноз поэтапной реализации этих мер. 
Области применения результатов: полученнье в рамках данного исследования результаты ичелесообразно использовать в анализе различных секторов экономики субъектов государства, и популяризацию применения энергоэффективных и энергосберегательных технологий в регионах.

Ключевые слова: энергоэффективные технологии; энергосбережение; промышиенный сектор; энерго-коммуникативные ресурсы; политика энергосбережения.

\section{IMPLEMENTATION OF THE REGIONAL ENERGY SAVING POLICY IN THE INDUSTRIAL SECTOR ON THE EXAMPLE OF THE VLADIMIR REGION}

\section{Kudryakov R.I.}

This study is devoted to the analysis and identification of the effectiveness of the regional energy conservation policy in the industrial sector of the Vladimir region. The article discusses the theoretical and conceptual apparatus, provides a detailed analysis of the use of energy efficient technologies in the industrial sector of the Vladimir region, with a procedure for assessing the effectiveness of current use and drawing up a forecast and recommendations for popularizing the use of such technologies in industrial production.

Purpose: highlighting the problems and potential in the current implementation of the regional energy conservation policy in the industrial sector of the Vladimir region, with the subsequent development of measures to stabilize the above negative aspects and forecasting efficiency.

Methods and methodology: a set of methods for theoretical justification (description, statistical analysis, comparison).

Results: the main problems are highlighted with the help of a comprehensive analysis of the use of energy efficient technologies in the industrial sector of the region, and a list of measures to stabilize the current problematic issues has been developed, and a forecast has been drawn up for the phased implementation of these measures. 
Practical implications: the results obtained in the framework of this study should be used in the analysis of various sectors of the economy of the subjects of the state, and in the popularization of the use of energy efficient and energy saving technologies in the regions.

Keywords: energy efficient technologies; energy saving; industrial sector; energy communication resources; energy saving policy.

\section{Введение}

В современных реалиях мира, в связи с высоким уровнем индустриализации, ресурсная база, используемая для создания товаров, постепенно истощается, что является одной из ключевых проблем в промышленном производстве.

Это связано с тем, что ресурсы необходимые для процесса производств не восстанавливаются, особенно относящиеся к группе природного происхождения [1, с.103-112]. Поэтому важность в использовании оптимального количества ресурсов и их экономии, является приоритетной задачей в условиях современного производства и общества.

Рассматривая данный факт, следует отметить, что в теоретическом аспекте, понятие ресурса многогранно, и оно классифицируется на определенные элементы [2, с. 141-142]. Например, С. Брю и К. Макконелл считают что ресурс - совокупность различных факторов необходимых для реализации идеи и выпуска готовой продукции [3, с. 45-51]. А Дж. Робинсон, считал что ресурс - это необходимый набор инструментов для создания продукта или услуги, с получением выгоды от их продажи [3, с. 59-67]. Однако, в процессе эволюции экономической науки, понятие ресурса на настоящий момент, интерпретируется следующим образом: это необходимые материальные, технологические, социальные, элементы, необходимые для процесса производства товара или услуги, направленное на получение максимального эффекта от его реализации. Так же, изучая теоретический аппарат, следует рассмотреть классификацию ресурсов на их разделы. Поэтому на рисунке 1 . Отражена классификация ресурсов по разделам. 


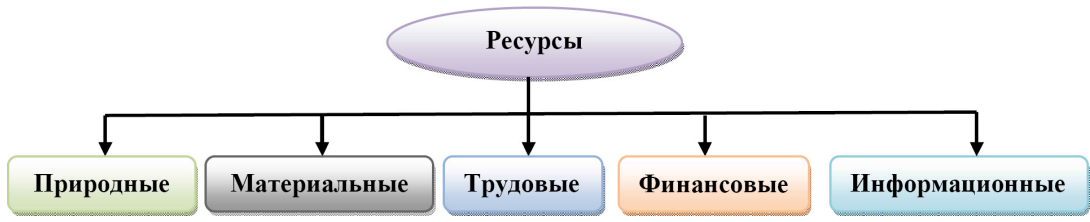

Рис. 1. Классификация ресурсов по разделам [3, с. 59-63]

Рассматривая классификацию, из рисунка 1 , следует выделить состав каждого из указанных выше элементов с помощью таблицы 1.

Таблица 1.

Состав элементов классификации ресурсов [3; с. 110-119]

\begin{tabular}{|l|l|}
\hline \multicolumn{1}{|c|}{$\begin{array}{c}\text { Категория } \\
\text { ресурса }\end{array}$} & \multicolumn{1}{c|}{ Состав элементов категории } \\
\hline Природные & $\begin{array}{l}\text { 1) Возобновляемые: (почва, леса, животные, и др.); } \\
\text { 2) Не возобновляемые: (металлы, нефть, газ, минералы, и др.); } \\
\text { 3) Неисчерпаемые: (солнечная энергия, вода, ветряная энер- } \\
\text { гия и др.). }\end{array}$ \\
\hline Материальные & $\begin{array}{l}\text { 1) Коммуникации: (электроэнергия, теплоэнергия, водо- } \\
\text { снабжение и др.); } \\
\text { 2) Строительные: (здания, дороги, и др.); } \\
\text { 3) Технические: (станки, оборудование, транспорт и др.) }\end{array}$ \\
\hline Трудовые & Человеческий капитал: (трудоспособное население) \\
\hline Финансовые & $\begin{array}{l}\text { Финансовые активы: (инвестиции, капитал, оборотные } \\
\text { средства и др.) }\end{array}$ \\
\hline Информационные & $\begin{array}{l}\text { Информационное обеспечение (правовая база, } \\
\text { информационное сопровождение, программное } \\
\text { обеспечение, и др.) }\end{array}$ \\
\hline
\end{tabular}

Исходя из данных полученных на основании таблицы 1, видно что, ресурсы подразделяются на подкатегории, которые отражают характер этих инструментов и принцип их использования. Рассматривая вопрос о ресурсах, и об их бережном использовании, на государственном уровне, ведутся работы по созданию методов и способов по рациональному применению ограниченных ресурсов в современном уровне производства, в особенности в энерго-коммуникативной сфере, которая относится ко второй категории классификации ресурсов. Одним из таких методов является применение 
энергоэффективных технологий в промышленном секторе, для экономии средств и уменьшения износа энергетических накопителей и преобразовательного оборудования, которые необходимы для создания продукта. Поэтому данная тема исследования является актуальной и обладает высокой практической значимостью.

\section{Цель исследования}

Проведение анализа при проведении региональной политики энергосбережения, выделения проблем при ее реализации, а также, составление оценки текущего уровня применения данных технологий, с выделением проблематики, и с последующей разработкой мероприятий по стабилизации вышеуказанных негативных аспектов.

\section{Методы и методология}

На основании полученных данных проведена оценка энергетического потребления в промышленном секторе Владимирской области с использованием индикатора идентифицирующего суммарные расходы энерго-коммуникативных ресурсов, в том числе, по одноставочному тарифу, что дает возможность их диагностировать по двум суточным зонам, с учетом выявленных ключевых проблем и рекомендаций по их устранению. Проведение детализированного анализа будет осуществляться на основе рассмотрения статистических данных за 2010-2020 г. по данным показателям потребления энерго-коммуникативных ресурсов, а также, энергетических затрат при использовании соответствующих ресурсов.

\section{Результат исследования}

Рассматривая вопрос об энергоэффективности, следует отметить, что в теоретическом понимании: энергоэффективность - это совокупность мер организационного, экономического и технологического характера, направленных на улучшения показателя рационального потребления энергетических ресурсов в хозяйственной деятельности в промышленной, научно-технологической, социально-бытовой сферах. Впервые, явление энергоэффективности описывалось в 1889 году с изобретением первого электросчетчика переменного тока, американ- 
ским инженером О. Шеленбергером [3, с. 97-103], по мнению автора, использование счетчика позволило отслеживать расход электроэнергии при ее потреблении и транспортировки. Однако, широкое использование этого метода началось в начале 70х годов XX века, когда потребление электрического переменного тока вышло на общемировой уровень использования, когда многие страны начали вводить политику энергоэффективности, с целью экономии средств на выработку и потребление необходимых видов ресурсов, к которым относятся: электрическая энергия, водоснабжение и водоотведение, тепловая энергия, газоснабжение, и др. [6, с. 104-111]. На данный момент, более 50\% общего потребления этих ресурсов приходится на социально-бытовую сферу, и более $45 \%$ на промышленное производство. Поэтому, для того что бы уменьшить нагрузку на энергоносители и уменьшить коэффициент нерационального потребления ресурсов, а также уменышить выбросы углекислого газа в атмосферу при сжигании углеводородного топлива, с целью получения энергии, был принят международный стандарт ISO 50001. Он регулирует вопросы по разработке, установки и модернизации, системы энергетического менеджмента включая в себя аспекты, связанные с энергоэффективностью, энергосбережением и энергетической безопасностью. Среди этих стран на третьем месте в рейтинге потребления энергетических ресурсов находится Российская Федерация (далее - РФ), так как, обширная территория и климатические условия страны, подразумевает большое энергетическое потребление во всех сферах хозяйственной деятельности. Поэтому с целью уменьшения энергоемкости и потребления энерго-коммуникативных ресурсов, в РФ, был принят Федеральный Закона (далее - Ф3) от 23 ноября 2009 г. №261, который рассматривает проведение политики энергосбережения и энергоэффективности, способствующих достижению поставленной выше цели. Несмотря на, создание Ф3 №261, действующий на федеральном уровне [9], практически в каждом регионе, создается программа реализации энергосберегающей политики, акцентируя приоритеты использования исходя из особенностей региона. В качестве примера реализации данной политики автором был выбран регион Владимирская область. 
Владимирская область территориально располагается в Центральном Федеральном Округе [10], в умеренно-континентальном климате, что указывает на повышенный спрос тепловой энергии в холодные времена года, а следовательно и увеличением энергетического потребления ресурсов. На рисунке 2 представлена динамика энергопотребления региона с 2010-2020 г.

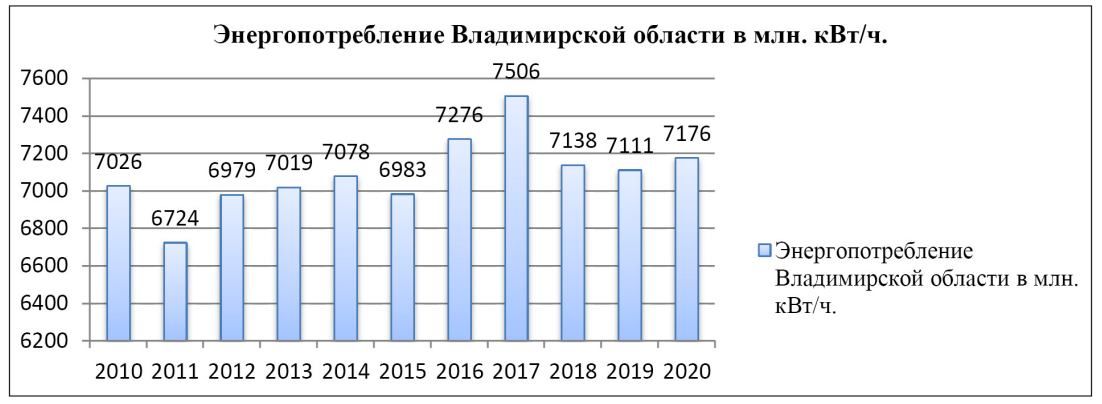

Pис. 2. Динамика энергопотребления Владимирской области за 2010-2020 г [4].

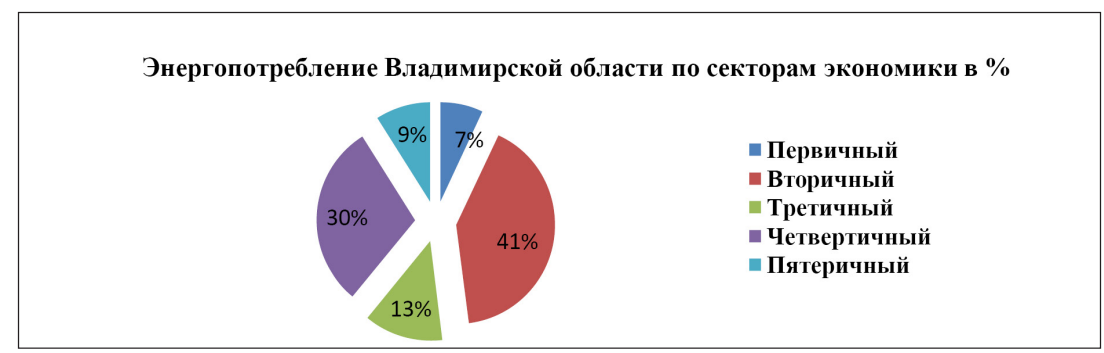

Рис. 3. Динамика энергопотребления Владимирской области по секторам экономики [5]

На основе данных полученных из рисунка 1, видно, что энергопотребление Владимирской области находится в экспонентной восходящей тенденции по уровню потребления электрической энергии. Для детального рассмотрения, автор рассматривает уровень энергопотребления в разделении на конкретные секторы экономики, используя теорию секторизации экономики ФишераКларка, с методологией Хатта и Брутто, которые представлены на рисунке 3. 
На рисунке 3, видно что использование энергии преимущественно занимает вторичный сектор экономики относящейся к промышленному производству, с показателем в $41 \%$, что является основной сферой предполагающей высокие затраты энергии, для производства товаров. Рассматривая энергопотребление промышленного сектора, автор выявил основные расходы энерго-коммуникативных ресурсов при производстве регионального продукта. Расчет данного показателя происходит по следующей формуле разработанной автором:

Где:

$$
\sum_{t=0} P E=E_{i} * T_{i}
$$

$[P E]$ - сумма расходов энерго-коммуникативных ресурсов при производстве регионального продукта;

$\left[E_{i}\right]-$ Количество энергетических ресурсов поставленных для производства;

$\left[T_{i}\right]$ - Количество человек занятых на производстве регионального продукта.

При расчете показателя получены следующие результаты:

$$
\left.\sum_{t=0} P E=20245 * 63000=1275435000\left(\frac{\kappa В \mathrm{~T}}{ч}\right) \approx 1275,435 \text { (млн. } \frac{\kappa В \mathrm{~T}}{ч}\right)
$$

Таблища 2.

Тариф на энергетические ресурсы во Владимирской области за 2020 г. [5]

\begin{tabular}{|l|l|l|l|}
\hline \multicolumn{1}{|c|}{ Категория тарифа } & $\begin{array}{c}\text { Единица } \\
\text { измерения }\end{array}$ & $\begin{array}{c}\text { В пределах нормы } \\
\text { потребления (цена) }\end{array}$ & $\begin{array}{c}\text { Сверх нормы } \\
\text { потребления } \\
\text { (цена) }\end{array}$ \\
\hline Одноставочный тариф & Руб/кВт/ч & 4,48 & 5,40 \\
\hline Одноставочный тариф дифференцированный по двум зонам суток <1> \\
\hline $\begin{array}{l}\text { Дневная зона } \\
\text { (пиковая и полупиковая) }\end{array}$ & Руб/кВт/ч & 5,15 & 6,21 \\
\hline Ночная зона & Руб/кВт/ч & 2,69 & 3,65 \\
\hline Одноставочный тариф дифференцируемый по трем зонам суток $<1>$ \\
\hline Пиковая зона & Руб/кВт/ч & 5,82 & 7,02 \\
\hline Полупиковая зона & Руб/кВт/ч & 4,48 & 5,40 \\
\hline Ночная зона & Руб/кВт/ч & 2,69 & 3,65 \\
\hline
\end{tabular}


Исходя из полученного результата, автор выявляет, что итоговые значения составляют 1/6 от всего объема энергопотребления области. Что является оптимальным средним значением данного показателя. Далее, автором представлены данные о тарифах, используемых на 2020 г. во Владимирской области, представленные в таблице 2.

Исходя из значений таблицы 2 , автор использует расчет стоимости поставленной энергии поставленной при производстве регионального продукта, по одноставочному тарифу, дифференцированному по двум зонам суток, используя дневную зону. Для проведения расчетов автор использовал следующую формулу разработанную им:

Где:

$$
\sum_{\text {pуб }} P E=\sum P E * T h_{i}
$$

$\left[T h_{i}\right]$ - единица тарифа в рублях.

При расчете получился следующий результат:

$$
\sum_{\text {руб }} P E=\sum 1275,5 * 5,15=6568,8 \text { млн. руб. }
$$

На основании данного расчета видно, что сумма финансовых средств обладает высокой ценностью, при формировании использованного потенциала энергоэффективных технологий в промышленном секторе, всего в размере $11 \%$, что является низким коэффициентом, в сравнении с Московской областью, где он равняется $23 \%$. Следовательно, региональная политика энергосбережения в промышленном секторе является недостаточно эффективной. Причина низкого индекса связана с со следующими факторами:

- Устаревшее оборудование на производствах: коэффициент полезного действия (далее - КПД), которого составляет менее $25 \%$, и уровень потребления энергии остается высоким;

- Увеличенное использование энергоемкостей, способствующих их высокому уровню износа и риска в потере работоспособности;

- Низкая мотивация у предпринимателей к использованию энергоэффективных технологий в производстве, так как механизм оптимального стимулирования недостаточно сформирован; 
- Высокие затраты связанные с заменой технического оснащения с улучшенным уровнем КПД более $75 \%$;

- Отсутствие механизма контроля за, исполнением программы проведения энергоэффективности на муниципальном, и федеральном уровне;

- Уменьшенный объем инвестиций в энергоэффективность из федерального бюджета и капитала частного характера, из-за высоких рисков связанных с инвестициями в данную сферу, и сложностью прогнозирования возврата таких финансовых вложений.

Все вышеуказанные факторы оказывают негативное влияние на проведение региональной политики энергосбережения. Рассматривая этот вопрос, автор выделил следующие способы по стабилизации текущей ситуации связанной с использованием энергоэффективности в промышленном секторе Владимирской области

- Проведение цикла мероприятий связанных с агитацией и популяризацией энергоэффективных технологий на муниципальном уровне, с представителями крупного бизнеса и инвесторами связанными высокотехнологическим направлением;

- Создать фонд, специализирующийся на выделении финансовых средств на закупку энергоэффективного оснащения, под условия лизинга;

- Предоставление налоговых льгот и преференций предпринимателям использующим энергоэффективное оборудование на производствах;

- Создать эффективный механизм контроля за, реализацией программы регионального уровня, связанной с проведением политики энергосбережения, и назначить орган государственной власти, ответственный за его надзор;

- На федеральном уровне, доработать нормативно-правовой аспект, включающий показатель минимального и обязательного использования таких технологий в производстве, с системой дестимуляции в виде штрафов за неисполнение обязательств;

- Предоставление инвесторам, осуществляющим вложения финансовых активов в энергоэффективные технологии опти- 
мальных и выгодных условий, связанных с частичным освобождением от налогов.

\section{Заключение}

Разработанные автором рекомендации, способствуют положительному влиянию на экономику региона, а именно: уровень вложения денежных средств, связанных с оплатой энерго-коммуникативных ресурсов снизятся на 40-50\%, произойдет сокращение их расходования таких ресурсов. Это снизит нагрузку на энергоемкости и уменьшит их износ, а также уменьшится, стоимость готовых изделий в производстве на готовые изделия, а сэкономленные средства сформируют страховой капитал, для сохранения хозяйственной деятельности организаций, например во время пандемии, или способствует диверсификации на развитие организаций, увеличивая индекс производства в промышленном секторе. На основании вышеизложенного, автор, сформировал прогноз, который обуславливает эффективность примененных мероприятий. Данный прогноз представлен на рисунке 3.

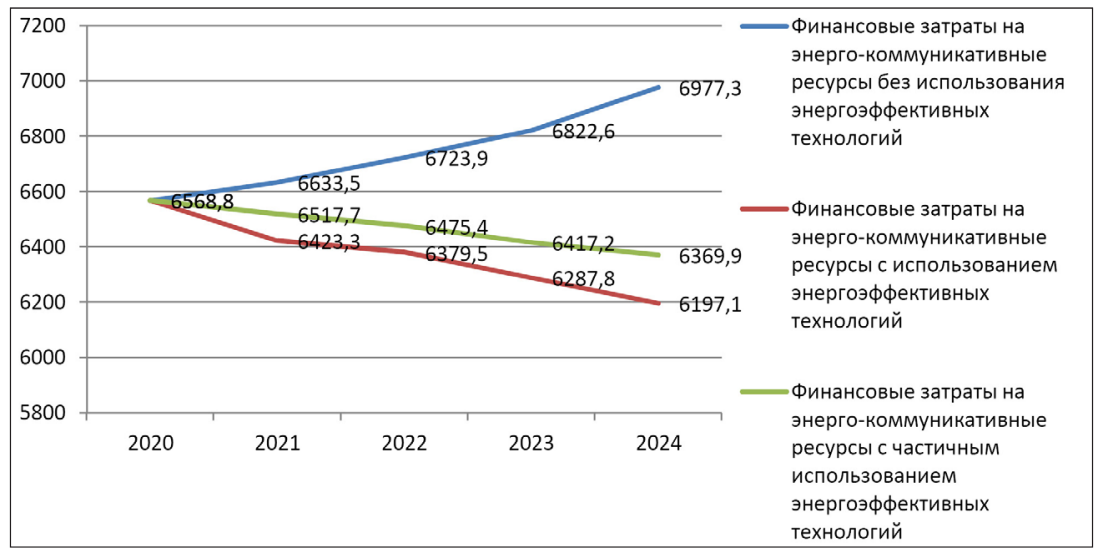

Рис. 3. Прогноз финансовых вложений в энерго-коммуникативные ресурсы без применения энергоэффективных технологий и с их использованием на среднесрочном периоде

Исходя из полученных данных прогноза, видно, что при использовании энергоэффективных технологий в промышленном секторе 
Владимирской области, при текущей цене использования, произойдет значительная экономия в региональном бюджете с показателем в 371 млн. рублей, тогда как без использования таких технологий расход денежных средств увеличится на 408,5 млн. рублей, что является высокой финансовой потерей.

На основании всего вышесказанного, следует отметить, что проведение политики энергосбережения в регионе обуславливает свою значимость и необходимость для улучшения развития как промышленного сектора, так и экономики региона в целом. При этом, применение рекомендаций сформированных автором, повысит потенциал и увеличит привлекательность к использованию энергоэффективных технологий в производстве, обуславливая положительный синергетический эффект от их внедрения.

\section{Список литературы}

1. Башмаков И.А. Энергетика России: стратегия инерции или стратегия эффективности? // Вопросы экономики. 2007. № 8. С. 104-122.

2. Башмаков И.А. Россия - 2050 // Вопросы экономики. 2008. № 8. С. 140-144.

3. Юн В.Г. Классификация и учёт природных ресурсов. М., 2005. $301 \mathrm{c}$.

4. Официальный сайт Федеральной службы государственной статистики по Владимирской области [Электронный ресурс]. Режим доступа: http://vladimirstat.old.gks.ru (дата обращения: 18.09.2020).

5. Официальный сайт Независимого института социальной политики [Электронный pecypc]. Режим доступа: http://www.socpol.ru (дата обращения: 18.09.2020).

6. Каменских М. А. Повышение конкурентоспособности региона на основе организации инновационной инфраструктуры / М. А. Каменских, В. П. Постников // Региональная экономика: теория и практика. 2013. № 2. С. 39-43.

7. Федеральный закон от 23 ноября 2009 г. N 261-Ф3 «Об энергосбережении и о повышении энергетической эффективности и о внесении изменений в отдельные законодательные акты Российской Федера- 
ции» (в действующей редакции от 26.06.2019 - «Российская газета», N 226, 27.11.2009).

8. Постановление Губернатора Владимирской области от 01.02.2012 N 94 «Об утверждении государственной программы «Энергосбережение и повышение энергетической эффективности во Владимирской области на период до 2020 года» (в ред. постановления администрации города Владимира от 19.06.2019 N 2699).

9. Кудряков Р.И. Анализ инновационного развития промышленного сектора Владимирской области при помощи теории графов // Наука Красноярья. 2020, Т.9, №1. С. 116-119.

10. Стенников В.А., Пеньковский А.В. Теплоснабжение потребителей в условиях рынка: современное состояние и тенденции развития // ЭКО. 2019. № 9. С. 48-69.

11. Омельченко Д.П., Уваров И.П. Энергосбережение и пути оптимизации использования электрической энергии // Современные проблемы науки и образования. 2014. № 6. http://science-education.ru/ ru/article/view?id=15936 (дата обращения: 07.11.2020).

12. Доманов В.И., Билалова А.И. Анализ прогнозирования энергопотребления с различными информационными базами // Известия Самарского научного центра Российской академии наук. 2014. Т. 16. № 4(3). C. 535-537.

13. Kuznetsov N.M. Energy Saving and Energy Audit // International J. Applied and Fundamental Research. 2013. No. 2. www.science-sd.com/45524108 (дата обращения: 07.11.2020).

14. Worrell E., Blinde P., Neelis M., Blomen E., and Masanet E. Energy Efficiency Improvement and Cost Saving Opportunities for the U.S. Iron and Steel industry: An ENERGY STAR $®$ Guide for Energy and Plant Managers, LBNL-4779E (Berkeley, CA: Lawrence Berkeley National Laboratory, Environmental Technologies Division, October 2010).

15. Paul D. "Modeling the U.S. Iron and Steel Industry," U.S. Energy Information Administration Task Order DE-DT0001606, Subtask 1.2 (Leidos: November 15, 2013).

16.D Paul. "Final Report: Modeling the U.S. Pulp and Paper Industry," U.S. Energy Information Administration Task Order 7965, Subtask 17 (Leidos: July 15, 2015). 
17.U.S. Department of Energy, Energy Efficiency and Renewable Energy, U.S. Energy Requirements for Aluminum Production: Historical Perspective, Theoretical Limits, and Current Practices (Washington, DC: February 2007).

18. Moon H.R., Weidner M. Linear regression for panel with unknown number of factors as interactive fixed effects. Econometrica, 2015, vol. 83 (5), iss. 4, pp. 1543-1579.

19. Baumeister C., Hamilton J. D. Sign restrictions, structural vector autoregressions, and useful prior information. Econometrica, 2015, vol. 83 (5), pp. 1963-1999.

20. Wied D. A Nonparametric test for a constant correlation matrix. Econometric Reviews, 2017, vol. 36, iss. 10, pp. 1157-1172.

\section{References}

1. Bashmakov I.A. Energetika Rossii: strategiya inertsii ili strategiya effektivnosti? [Power Industry of Russia: Strategy of Inertia or Strategy of Efficiency?] Voprosy ekonomiki [Economic Issues]. 2007. No. 8, pp. 104-122.

2. Bashmakov I.A. Russia - 2050. Voprosy ekonomiki [Economic Issues]. 2008. No. 8, pp. 140-144.

3. Yun V.G. Klassifikatsiya i uchet prirodnykh resursov [Classification and accounting of natural resources]. M., 2005. $301 \mathrm{p}$.

4. Official site of the Federal State Statistics Service for the Vladimir region [Electronic resource]. http://vladimirstat.old.gks.ru (accessed: 09/18/2020).

5. Official site of the Independent Institute for Social Policy [Electronic resource]. http://www.socpol.ru (accessed: 18.09.2020).

6. Kamenskikh M. A., Postnikov V. P. Povyshenie konkurentosposobnosti regiona na osnove organizatsii innovatsionnoy infrastruktury [Increasing the competitiveness of the region based on the organization of innovative infrastructure]. Regional 'naya ekonomika: teoriya i praktika [Regional economy: theory and practice]. 2013. No. 2, pp. 39-43.

7. Federal Law of November 23, 2009 N 261-FZ "On Energy Saving and on Increasing Energy Efficiency and on Amendments to Certain Leg- 
islative Acts of the Russian Federation" (as amended on 26.06.2019 "Rossiyskaya Gazeta", N 226, 27.11.2009).

8. Resolution of the Governor of the Vladimir region of 01.02.2012 N 94 " On approval of the state program" Energy conservation and energy efficiency in the Vladimir region for the period until 2020 " (as amended by the resolution of the administration of the city of Vladimir of 19.06.2019 N 2699).

9. Kudryakov R.I. naliz innovatsionnogo razvitiya promyshlennogo sektora Vladimirskoy oblasti pri pomoshchi teorii grafov [Analysis of the innovative development of the industrial sector of the Vladimir region using graph theory]. Nauka Krasnoyar'ya [Science of Krasnoyarsk]. 2020, V.9., No. 1, pp. 116-119.

10. Stennikov V.A., Penkovsky A.V. Pen'kovskiy A.V. Teplosnabzhenie potrebiteley $\mathrm{v}$ usloviyakh rynka: sovremennoe sostoyanie $\mathrm{i}$ tendentsii razvitiya [Heat supply to consumers in the market conditions: current state and development trends]. EKO. 2019. No. 9, pp. 48-69.

11. Omelchenko D.P., Uvarov I.P. Energosberezhenie i puti optimizatsii ispol'zovaniya elektricheskoy energii [Energy saving and ways to optimize the use of electrical energy]. Sovremennye problemy nauki i obrazovaniya [Modern problems of science and education]. 2014. No. 6. http://science-education.ru/ru/article/view?id=15936 (date accessed: 11/07/2020).

12. Domanov V.I., Bilalova A.I. Analiz prognozirovaniya energopotrebleniya s razlichnymi informatsionnymi bazami [Analysis of forecasting energy consumption with various information bases]. Izvestiya Samarskogo nauchnogo tsentra Rossiyskoy akademii nauk [News of the Samara Scientific Center of the Russian Academy of Sciences]. 2014. V. 16. No. 4 (3), pp. 535-537.

13. Kuznetsov N.M. Energy Saving and Energy Audit. International J. Applied and Fundamental Research. 2013. No. 2. www.science-sd. com/455-24108 (accessed: 11/07/2020).

14. Worrell E., Blinde P., Neelis M., Blomen E., and Masanet E. Energy Efficiency Improvement and Cost Saving Opportunities for the U.S. Iron and Steel industry: An ENERGY STAR ${ }^{\circledR}$ Guide for Energy and Plant Managers, LBNL-4779E (Berkeley, CA: Lawrence Berkeley National Laboratory, Environmental Technologies Division, October 2010). 
15. Paul D. "Modeling the U.S. Iron and Steel Industry," U.S. Energy Information Administration Task Order DE-DT0001606, Subtask 1.2 (Leidos: November 15, 2013).

16. Paul D. "Final Report: Modeling the U.S. Pulp and Paper Industry," U.S. Energy Information Administration Task Order 7965, Subtask 17 (Leidos: July 15, 2015).

17.U.S. Department of Energy, Energy Efficiency and Renewable Energy, U.S. Energy Requirements for Aluminum Production: Historical Perspective, Theoretical Limits, and Current Practices (Washington, DC: February 2007).

18. Moon H. R., Weidner M. Linear regression for panel with unknown number of factors as interactive fixed effects. Econometrica, 2015, vol. 83 (5), iss. 4, pp. 1543-1579.

19. Baumeister C., Hamilton J. D. Sign restrictions, structural vector autoregressions, and useful prior information. Econometrica, 2015, vol. 83 (5), pp. 1963-1999.

20. Wied D. A Nonparametric test for a constant correlation matrix. Econometric Reviews, 2017, vol. 36, iss. 10, pp. 1157-1172.

\section{ДАННЫЕ ОБ АВТОРЕ}

Кудряков Роман Игоревич, старший преподаватель кафедры «международного права и внешнеэкономической деятельности»

ФГБОУ ВО «Владимирский государственный университет имени А.Г. и Н.Г. Столетовых

Ул. Горького, 87, г. Владимир, 600000, Российская Федерачия r.kudryakov-vlsu@bk.ru

\section{DATA ABOUT THE AUTHOR}

Kudryakov Roman Igorevich, Senior Lecturer, Department of "International Law and Foreign Economic activity" Vladimir State University named after A.G. and N.G. Stoletovs 87, Gorky Str., Vladimir, 600000, Russian Federation r.kudryakov-vlsu@bk.ru 